\title{
Multi-Parameter Layup Optimization and the Effect of Layup Homogenization on the Bending Compliance Matrix of Coupled Composites
}

\author{
Brúnó Vermes ${ }^{1,2}$, Tibor Czigany ${ }^{1,2 *}$ \\ ${ }^{1}$ Department of Polymer Engineering, Faculty of Mechanical Engineering, Budapest University of Technology and Economics, \\ H-1111 Budapest, Múegyetem rkp. 3., Hungary \\ ${ }^{2}$ MTA-BME Research Group for Composite Science and Technology, H-1111 Budapest, Műegyetem rkp. 3., Hungary \\ *Corresponding author, e-mail: czigany@eik.bme.hu
}

Received: 14 December 2021, Accepted: 04 January 2022, Published online: 02 February 2022

\begin{abstract}
The behaviour of fibre-reinforced composites greatly depends on their layup structures. Through a full-field layup optimization study based on multiple parameters, this paper investigates how different properties change with the layup. The aim was to maximize the extension-twist coupling performance while ensuring adequate bending stiffness and low thermal warpage to make the laminate suitable for shape-adaptive helicopter rotor blade application. The Classical Laminate Theory-based calculations revealed that satisfying the bending compliance and thermal warpage criteria significantly limited the achievable extension-twist performance. The warpage limit affected the desired coupling behaviour more because both properties are driven by terms in the extensionalbending compliance matrix, unlike bending compliance. Symmetric laminates do not have an intrinsic extension-twist capability, but some asymmetric laminates demonstrated significant coupling performance while being practically warpage-free (based on the ISO2768 standard). The results prove that the advantages of asymmetric laminates can outweigh their sometimes negligible disadvantages. The paper also investigates if there is a universal tendency in how layup homogenization affects the terms of the bending compliance matrix of composites. Through analytical calculations, we showed that depending on the layup of the sublaminate, homogenization can increase or reduce the value of any term in the bending compliance matrix; therefore, there is no universal tendency. Based on these results, layup homogenization cannot only be exploited for its most general purpose - warpage mitigation - but also for improving other characteristics of the laminate (e.g. reducing the bending compliance for increased bending stiffness or increasing the bend-twist compliance for improved coupling performance).
\end{abstract}

Keywords

coupled composites, layup optimization, layup homogenization, classical laminate theory

\section{Introduction}

Composites - especially fibre reinforced ones - are mainly used in the industry due to the excellent strength and stiffness they can provide while also being lightweight. The outstanding specific mechanical properties result not only from the properties of the constituting fibre and matrix materials but also the orthotropic structure of the plies. Fibres can be oriented in the directions where more significant strength and stiffness are required while keeping the amount of reinforcement low in the secondary directions, thereby saving weight.

However, the value of composites can be further increased by improving other properties of the material, too. Many research projects have focused on increasing the ductility of composites to mitigate one of the most significant disadvantages of these materials: brittle failure. Amongst others, notable pseudo-ductile results were achieved with hybrid [1], angle-ply [2], and inter-layer modification [3] approaches. Besides improving certain properties of composites (e.g. ductility $[4,5]$, impact resistance $[6,7]$ or fire retardancy $[8,9])$, they can be endowed with additional functionalities that can increase their advantage over competing structural materials. The additional functions can range from self-healing $[10,11]$ to integrated health monitoring $[12,13]$, but the coupled behaviour of composites might be the most fundamental of all. Coupling refers to a direct connection between loads and deformations of 
different modes (e.g. twisting deformation as a result of tensile loading). A composite can have many coupling connections (e.g. extension-bend, extension-twist or bend-twist). This morphing (or shape-changing) functionality of the material is fundamental in the sense that it can be achieved by carefully designing the layup without the need for any additional material. Due to the significance of non-conventionally shape-changing structural materials, coupled laminates not only have extensive scientific literature [14-16] but there are industrial examples for their utilization, too. They are most commonly used in morphing turbine blades. With an extension-twist helicopter blade or a bend-twist marine propeller, the aerodynamic or hydrodynamic efficiency can be significantly improved by designing the layup to achieve optimal shape adaptation under loading [17-20].

However, during the layup design process, not only mechanical loads but factors such as moisture absorption [21] or thermal expansion [22] have to be considered, too, because stresses arising from these can lead to warpage in orthotropic structures. The majority of the possible layup permutations of composites - and especially coupled composites - are asymmetric to their mid-plane, and asymmetry usually leads to unwanted thermal warpage. There are asymmetric laminates that do not warp, but these are very rare [23, 24]. Therefore, warpage mitigation needs to be considered during the layup optimization process. In such a multi-parameter optimization, only those layups that satisfy the maximum limit of thermal warpage would compete against each other, based on the rest of the criteria - such as coupling performance.

Another approach to mitigate warpage is layup homogenization $[25,26]$. During homogenization, identical sub-laminates are stacked upon each other through the thickness of the composite. The sub-laminates can be asymmetric, as the effect of asymmetry (and therefore warpage) quickly decreases with the increasing level of homogenization (increasing number of sub-laminate repetitions) [27]. However, homogenization also has its limits. If two laminates with the same plies (material, number and orientations) only differ in the level of their homogenization (e.g. $\left[0_{8} / 90_{8}\right]$ non-homogenized and $[0 / 90]_{8}$ homogenized), the values of the extensional-bending coupling compliance matrix ([b]), based on the Classical Laminate Theory) of the more homogenized laminate will be lower. This is why homogenization mitigates warpage, but it also means that it mitigates all the coupling terms in that matrix. In fact, the $[b]$ matrix values rapidly converge to zero with homogenization. As the constituting plies are the same in the two cases, the extensional compliance matrix ([a]) remains unchanged. However, it has not been published yet how the terms of the bending compliance matrix ([d]) change with layup homogenization. It needs to be investigated if there is a general tendency for the $[d]$ matrix terms as there is for the $[a]$ and the $[b]$ matrix terms.

In certain situations - such as the mechanical optimization of beam-like structures - composite beam theories $[28,29]$ can be more advantageous than plate theories. However, because of their universality, we focus on plates and shape-changing behaviour resulting from the layup structure of those plates.

Based on the above, this paper has two aims. First, to demonstrate a multi-parameter layup optimization process of coupled laminates where one of the objectives is to keep thermal warpage practically negligible. And second, to prove or disprove if there is a general tendency in how the values of the bending compliance $([d])$ matrix terms change with the effective warpage mitigation method of layup homogenization.

\section{Methods and material}

All calculations in this paper are based on the Classical Laminate Theory (CLT), where the $6 \times 6[a b d]$ compliance matrix (Eq. (1)) establishes the relations between the different loads ( $N$ : forces per unit width and $M$ : moments per unit width, Fig. 1) and deformations ( $\varepsilon^{0}$ : mid-plane strains and $\kappa$ : curvatures) [30].

$\left[\begin{array}{c}\varepsilon_{x x}^{0} \\ \varepsilon^{0}{ }_{y y} \\ \varepsilon_{x y}^{0} \\ \kappa_{x x} \\ \kappa_{y y} \\ \kappa_{x y}\end{array}\right]=\left[\begin{array}{llllll}a_{11} & a_{12} & a_{16} & b_{11} & b_{12} & b_{16} \\ a_{12} & a_{22} & a_{26} & b_{21} & b_{22} & b_{26} \\ a_{16} & a_{26} & a_{66} & b_{61} & b_{62} & b_{66} \\ b_{11} & b_{21} & b_{61} & d_{11} & d_{12} & d_{16} \\ b_{12} & b_{22} & b_{62} & d_{12} & d_{22} & d_{26} \\ b_{16} & b_{26} & b_{66} & d_{16} & d_{26} & d_{66}\end{array}\right]\left[\begin{array}{l}N_{x x} \\ N_{y y} \\ N_{x y} \\ M_{x x} \\ M_{y y} \\ M_{x y}\end{array}\right]$

Equation (1) works for thermal loads, too, where the thermal forces and moments per unit width are calculated from

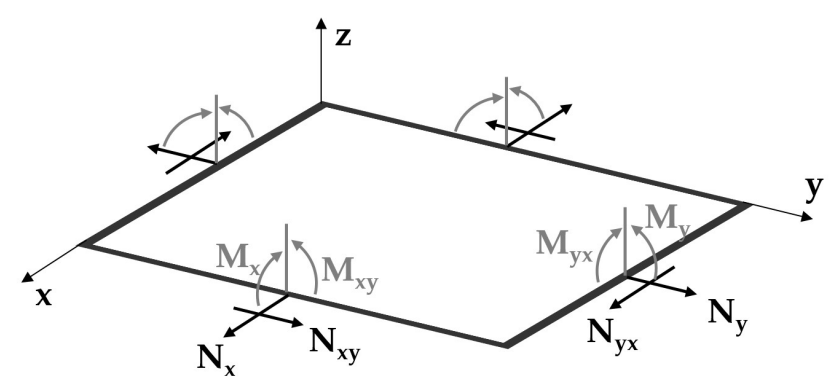

Fig. 1 Illustration of the forces and moments per unit width acting on the unit plate element (based on $[25,30]$ ) 
the change in temperature, the layup and the material properties of the constituting plies [25]. From the curvatures, the out-of-plane displacements (deflections) can be calculated at each point of the laminate based on Eq. (2), where $w$ is the deflection and $x$ and $y$ are the in-plane coordinates [25].

$w(x, y)=-\frac{\kappa_{x x}}{2} x^{2}-\frac{\kappa_{y y}}{2} y^{2}-\frac{\kappa_{x y}}{2} x y$

The extent of warpage is quantified in this paper as the difference between the maximum and the minimum value of the out-of-plane deflection of a $150 \mathrm{~mm} \times 150 \mathrm{~mm}$ laminate with a fixed mid-point. This is equivalent to the height of the encasing cuboid of the warped laminate (Fig. 2a)), where larger heights indicate more significantly warped laminates. It has to be noted that this CLT-based calculation method always predicts the warped laminate to be monostable and saddle-shaped. In reality, warped laminates can be bistable with two stable cylindrical shapes [31,32]. There are more advanced CLTbased approaches that can take bistability or even complex boundary conditions into account. Bistability can be
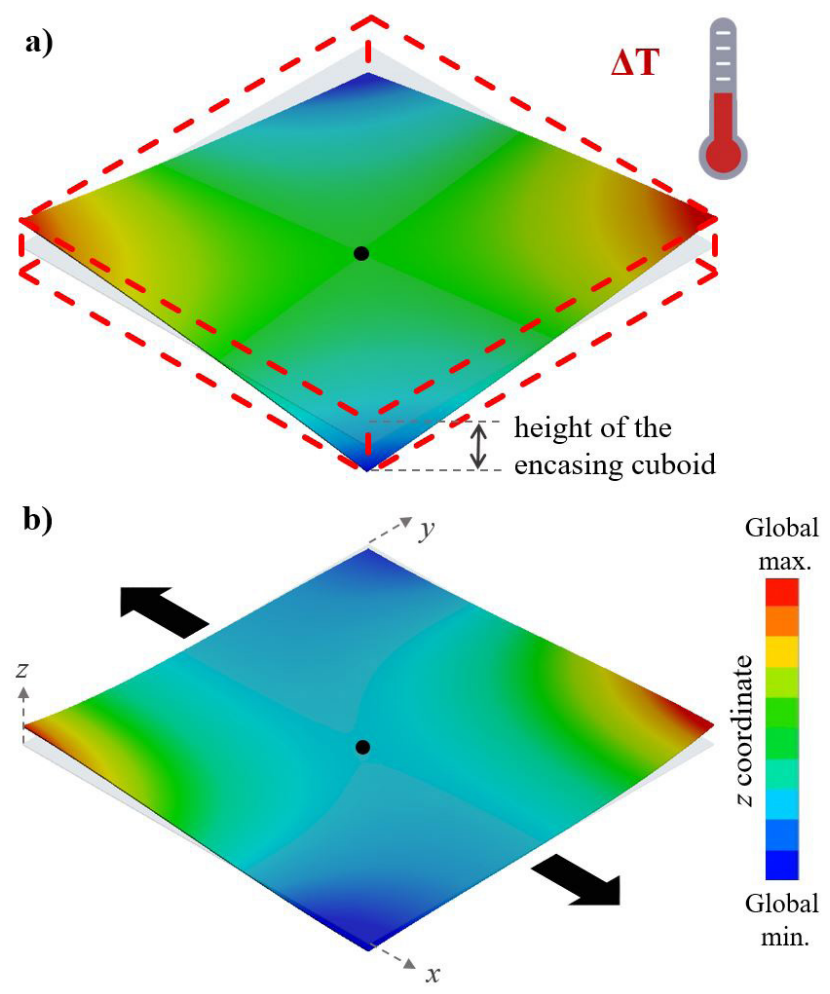

Fig. 2 Illustration of the a) thermal warpage and b) the extension-twist behaviour of a laminate. a) fixed laminate mid-point and thermal loading $\left(\Delta T=-115^{\circ} \mathrm{C}\right) ; \mathrm{b}$ ) fixed laminate mid-point and $N_{x}$ loading (image taken at $0.1 \%$ in-plane strain). Finite element results for the $150 \mathrm{~mm} \times 150 \mathrm{~mm}$ [0/0/15/15] laminate (layup selection based on Fig. 5). For visualization purposes only; 20x scaling for warpage in the $z$-direction modelled through finite element analysis, for instance, but it is not addressed in this paper in order to make a full-field analysis of a large number of layup permutations possible.

Fig. 2 illustrates an example of laminate warpage and the extension-twist behaviour. CLT results were calculated for all possible layup permutations of a 4-ply IM7/913 carbon-epoxy laminate with an orientation increment of $15^{\circ}$, which resulted in 20736 different layups. Due to the required computational effort, we carried out the optimization process with a self-developed CLT based algorithm in MATLAB environment. Table 1 contains the relevant properties of the unidirectional carbon-epoxy material, where $E_{1}, E_{2}$ and $G_{12}$ are the longitudinal, transverse and shear moduli, $v_{12}$ is the Poisson's ratio, and and are the longitudinal and transverse thermal expansion coefficients, respectively (all in-plane).

\section{Results and discussion}

This section first discusses two two-parameter and a three-parameter layup optimization study of coupled laminates, and then the effect of layup homogenization on the $[d]$ matrix values.

\subsection{Multi-parameter layup optimization}

As an example, the goal of the optimization study is to maximize the extension-twist performance of a 4-ply laminate so that it can provide an aerodynamic advantage when used as the material of a shape-adaptive helicopter rotor blade. The two other parameters considered in the optimization are warpage and bending stiffness. Low (or negligible) thermal warpage and sufficient bending stiffness are both essential for the composite to be usable in a rotor blade. For better demonstration, extension-twist performance is first discussed together with warpage, then bending stiffness and finally, both.

\subsubsection{Extension-twist $v s$. warpage}

Extension-twist performance is quantified by the magnitude of the extension-twist coupling compliance term $\left(b_{16}\right)$ of the composite, while warpage is quantified by the height of the encasing cuboid of the warped $150 \mathrm{~mm} \times 150 \mathrm{~mm}$ laminate. Warpage was calculated for a temperature change of $\Delta T=-115^{\circ} \mathrm{C}$, which represents the cooling stage

Table 1 Relevant properties of the Hexcel IM7/913 carbon-epoxy material

\begin{tabular}{ccccccc}
\hline $\begin{array}{c}\mathrm{E}_{1} \\
(\mathrm{GPa})\end{array}$ & $\begin{array}{c}\mathrm{E}_{2} \\
(\mathrm{GPa})\end{array}$ & $\begin{array}{c}\mathrm{G}_{12} \\
(\mathrm{GPa})\end{array}$ & $\begin{array}{c}v_{12} \\
(-)\end{array}$ & $\alpha_{0}\left({ }^{\circ} \mathrm{C}^{-1}\right)$ & $\alpha_{90}\left({ }^{\circ} \mathrm{C}^{-1}\right)$ & $\begin{array}{c}\text { Cured ply } \\
\text { thickness } \\
(\mathrm{mm})\end{array}$ \\
\hline 163.30 & 8.74 & 4.50 & 0.30 & $3.0 \times 10^{-7}$ & $3.2 \times 10^{-5}$ & 0.13 \\
\hline
\end{tabular}


of the autoclave curing cycle of the IM7/913 prepreg from $140{ }^{\circ} \mathrm{C}$ to room temperature $\left(25^{\circ} \mathrm{C}\right)$. Fig. 3 illustrates the extension-twist performance and the extent of thermal warpage for the layup permutations. Twisting can occur in two directions, but for better visualization, the absolute value of $b_{16}$ is illustrated. There are two upper limits of warpage in Fig. 3: a strict limit and a less strict limit. The strict limit is based on the L class of the ISO 2768 standard [33], maximizing the out-of-plane deflections of practically flat $150 \mathrm{~mm} \times 150 \mathrm{~mm}$ plates in $0.8 \mathrm{~mm}$. The less strict limit allows a five times larger warpage $(4 \mathrm{~mm})$, which was arbitrarily chosen to distinguish laminates with small but not negligible warpage. Although globally, the maximum extension-twist performance can be achieved with the [30/90/90/-30] layup, it is also one of the most significantly warping laminates. The two optimums are the [15/30/-30/-15] and the [0/0/15/15] layups satisfying the less strict and the strict warpage limits, respectively. With a less strict warpage limit, $64.9 \%$ of the maximum possible desired coupling performance can be achieved, but this decreases to only $28.4 \%$ when the strict warpage limit is satisfied. Also, some correlation between the desired coupling performance and warpage can be observed in the pattern in Fig. 3. The explanation for this is that both forms of behaviour depend on the values of the $[b]$ matrix. As the [b] matrix values are zero in the case of symmetric laminates, those laminates are in the origin of the graph, and all the other markers in Fig. 3 represent asymmetric laminates that traditionally would not be used in the industry due to their thermal warpage. However, the results demonstrate

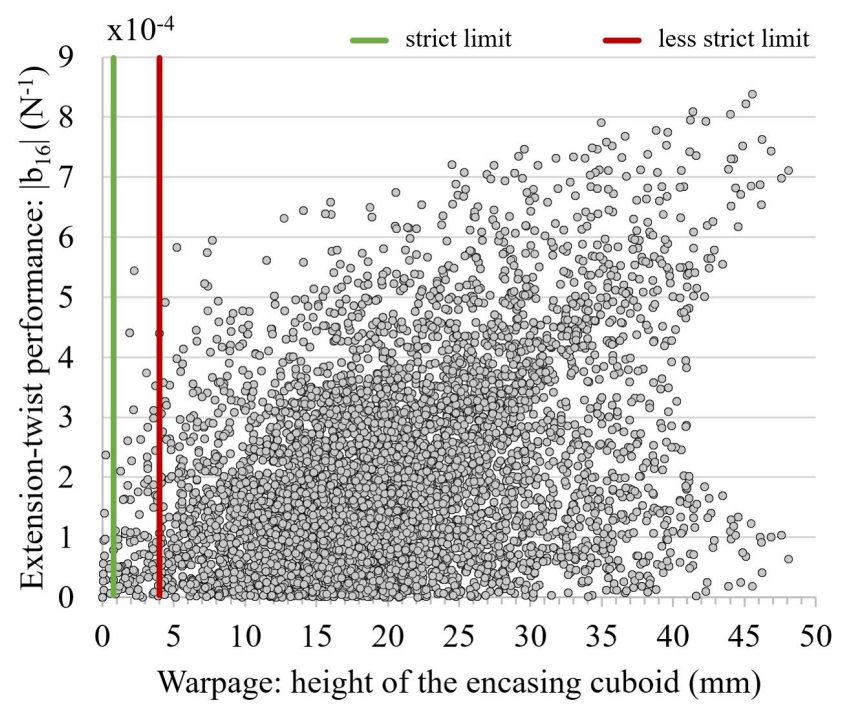

Fig. 3 Extension-twist performance $v s$. warpage $\left(\Delta T=-115^{\circ} \mathrm{C}\right)$ of $150 \mathrm{~mm} \times 150 \mathrm{~mm} 4$-ply IM7/913 carbon-epoxy laminates. Strict warpage limit: $0.8 \mathrm{~mm}$ [33], less strict warpage limit: $4 \mathrm{~mm}$ that many asymmetric laminates have negligible thermal warpage and therefore can be used in real-world structures.

\subsubsection{Extension-twist vs. bending compliance}

Sufficient bending stiffness of a structure that needs to withstand bending loads is an essential requirement. Instead of lower limits of the required bending stiffness, upper limits of the bending compliance $\left(d_{11}\right)$ can be defined. For the sake of clear visualization, the two limits of $d_{11}$ in this paper are chosen to be two times (strict) and five times (less strict) the magnitude of what can be minimally achieved with only $0^{\circ}$ plies. Fig. 4 illustrates the extension-twist performance of the layup permutations as a function of the bending compliance. By comparing the first two figures, it can be seen that extension-twist has a significantly weaker correlation with bending compliance than with warpage. This is because - based on CLT - the layup structure affects the $[b]$ and the $[d]$ sub-matrices of the $[a b d]$ matrix differently. The optimal layup that satisfies the less strict bending compliance limit ([30/75/-75/-30]) provides $96.0 \%$ of the maximum possible $b_{16}$ value. For the strict limit, the optimal layup is [15/75/-75/-15] with $75.6 \%$ of the maximum achievable extension-twist performance.

\subsubsection{Extension-twist vs. bending compliance vs. warpage} Ideally, all critical properties of the material are considered together in a multi-parameter layup optimization process. Fig. 5 illustrates the three-dimensional layup optimization space, where all layup permutations are visualized by their extension-twist performance, bending compliance and

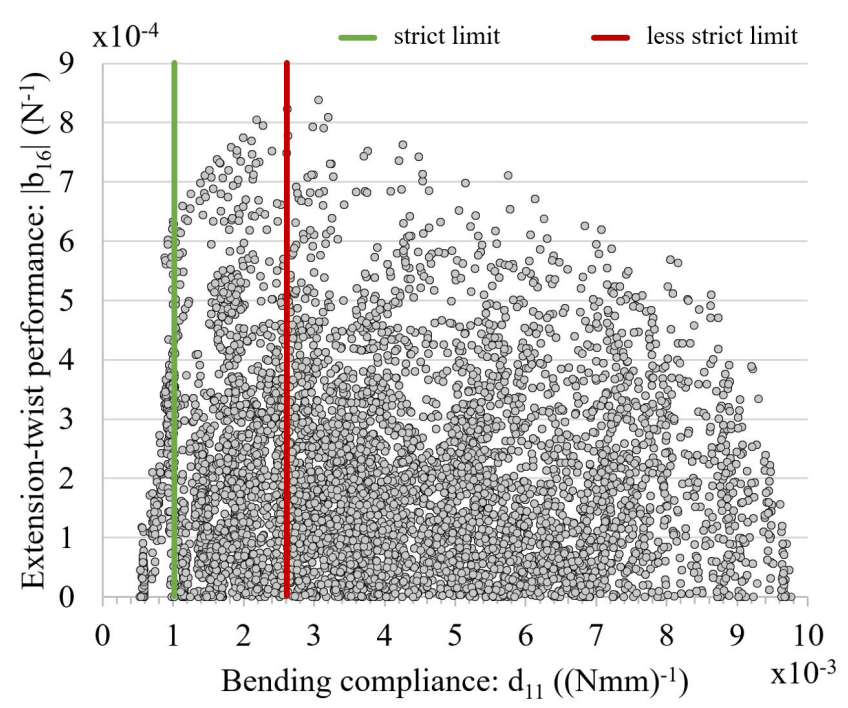

Fig. 4 Extension-twist performance $v s$. bending compliance. Strict bending compliance limit: $1.046 \times 10^{-3}(\mathrm{Nmm})^{-1}$, less strict bending compliance limit: $2.615 \times 10^{-3}(\mathrm{Nmm})^{-1}$ 


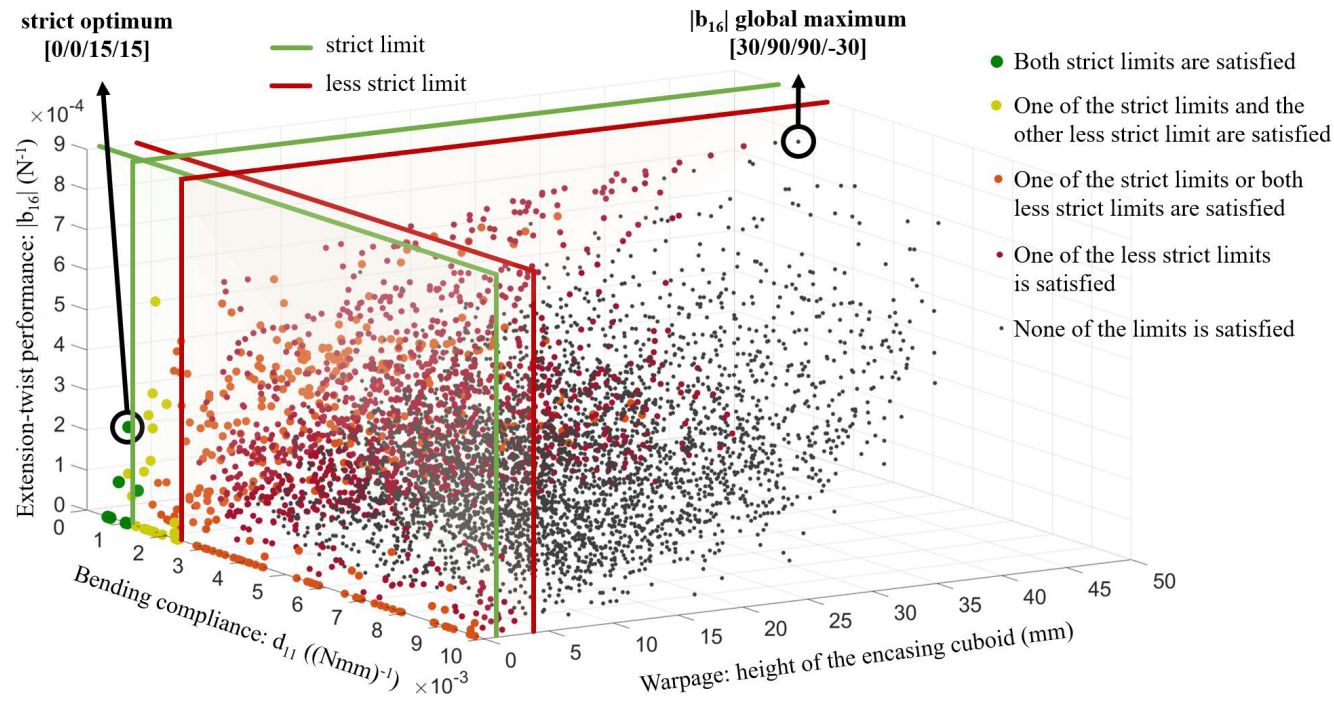

Fig. 5 Extension-twist performance $v s$. bending compliance $v s$. warpage $\left(\Delta T=-115^{\circ} \mathrm{C}\right)$ of $150 \mathrm{~mm} \times 150 \mathrm{~mm}$ 4-ply IM7/913 carbon-epoxy laminates. Strict bending compliance limit: $1.046 \times 10^{-3}(\mathrm{Nmm})^{-1}$, less strict bending compliance limit: $2.615 \times 10^{-3}(\mathrm{Nmm})^{-1}$. Strict warpage limit: $0.8 \mathrm{~mm}$ [33], less strict warpage limit: $4 \mathrm{~mm}$

warpage. In the case of four or more parameters, the optimization process is carried out the same way; only visualization becomes problematic. The limits are now planes that divide the space into nine divisions as both bending compliance and warpage have three levels of sufficiency. They either satisfy the prescribed strict limit, the less strict limit, or neither. In each division, the local optimum of the layups is the one with the most significant extension-twist performance. Table 2 summarizes the optimal layups from each division and their performance based on the three parameters. The last column of Table 2 contains one of the key results: the magnitude of the desired extension-twist coupling behaviour of the local optimum layups relative to the maximum achievable $b_{16}$, in percentage. The [0/0/15/15] layup satisfies the strict limits of both bending compliance and warpage, but provides only $28.4 \%$ of the achievable extension-twist performance. It is also worth noting that limiting one of the parameters does not always reduce the coupling performance. For instance, if warpage needs to stay below $4 \mathrm{~mm}$ (less strict limit), then the optimal layup is [15/30/-30/-15], which satisfies the strict limit of bending compliance and provides $64.9 \%$ of $b_{16}$. Allowing the bending compliance to be larger would not yield any performance benefit, as in this case, warpage is the controlling parameter.

\subsection{Layup homogenization vs. bending compliance matrix}

Based on the previous sections, the majority of the layup permutations can not be taken into consideration due to the extent of their warpage. However, layup homogenization can mitigate the warpage of any sub-laminate by repeating it through the thickness of the laminate. Warpage is mitigated because of the decreasing values of the laminate's

Table 2 Bending compliance $\left(d_{11}\right)$, warpage and extension-twist performance $\left(\left|b_{16}\right|\right)$ of the local optimum layups from each division based on Fig. 5

\begin{tabular}{|c|c|c|c|c|c|c|}
\hline$d_{11}$ limit satisfied & $\begin{array}{l}\text { Warpage limit } \\
\text { satisfied }\end{array}$ & Optimal layup & $d_{l l}\left((\mathrm{Nmm})^{-1}\right)$ & $\begin{array}{l}\text { Warpage }- \text { the height of } \\
\text { the encasing cuboid }(\mathrm{mm})\end{array}$ & $\left|b_{16}\right|\left(\mathrm{N}^{-1}\right)$ & $\begin{array}{l}\left|b_{16}\right| /\left|b_{16}\right|_{\max } \\
\times 100(\%)\end{array}$ \\
\hline Strict & Strict & {$[0 / 0 / 15 / 15]$} & $9.70 \times 10^{-4}$ & 0.23 & $2.38 \times 10^{-4}$ & 28.4 \\
\hline Strict & Less strict & {$[15 / 30 /-30 /-15]$} & $9.99 \times 10^{-4}$ & 2.22 & $5.44 \times 10^{-4}$ & 64.9 \\
\hline Less strict & Strict & {$[30 / 15 / 30 / 15]$} & $2.18 \times 10^{-3}$ & 0.07 & $3.88 \times 10^{-4}$ & 4.6 \\
\hline Less strict & Less strict & {$[0 / 15 /-45 /-30]$} & $1.64 \times 10^{-3}$ & 1.93 & $4.41 \times 10^{-4}$ & 52.6 \\
\hline Strict & - & {$[15 / 75 /-75 /-15]$} & $1.00 \times 10^{-3}$ & 33.29 & $6.34 \times 10^{-4}$ & 75.6 \\
\hline- & Strict & {$[45 / 45 / 60 / 60]$} & $7.63 \times 10^{-3}$ & 0.12 & $1.40 \times 10^{-4}$ & 16.7 \\
\hline Less strict & - & {$[30 / 75 /-75 /-30]$} & $2.18 \times 10^{-3}$ & 44.03 & $8.04 \times 10^{-4}$ & 96.0 \\
\hline- & Less strict & {$[30 /-75 /-15 / 60]$} & $4.01 \times 10^{-3}$ & 3.70 & $3.53 \times 10^{-4}$ & 42.1 \\
\hline - & - & [30/90/90/-30] & $3.06 \times 10^{-3}$ & 45.54 & $8.38 \times 10^{-4}$ & 100.0 \\
\hline
\end{tabular}


extensional-bending compliance matrix ([b]) with homogenization. This means that the extension-twist performance of the laminate decreases, too. Therefore, layup homogenization is not a universal solution to warpage, and its advantages depend on the application scenario. As mentioned before, the method leaves the $[a]$ matrix unchanged and reduces the $[b]$ matrix rapidly. The question is if there is a general tendency in how homogenization affects the values of the $[d]$ matrix.

Proving a general tendency is always trickier than disproving it, as the latter only requires a counterexample of the hypothetical general tendency. Therefore, we started to look at how the six $[d]$ matrix terms change with homogenization in different laminates, looking for opposite tendencies. As a baseline, we carried out a layup optimization study for maximum bend-twist performance $\left(d_{16}\right)$. We found that it was enough to compare the optimal [-30/90/90/-30] sub-laminate to its "inverse" counterpart, the [90/-30/-30/90] sub-laminate to disprove any general tendency in how the $[d]$ matrix values change with homogenization. Fig. 6 illustrates that $[d]$ matrix values that decrease in one case increase in the other and vice versa. This example proves that there is no universal tendency in how layup homogenization affects the $[d]$ matrix values, as it depends on the layup of the sub-laminate.
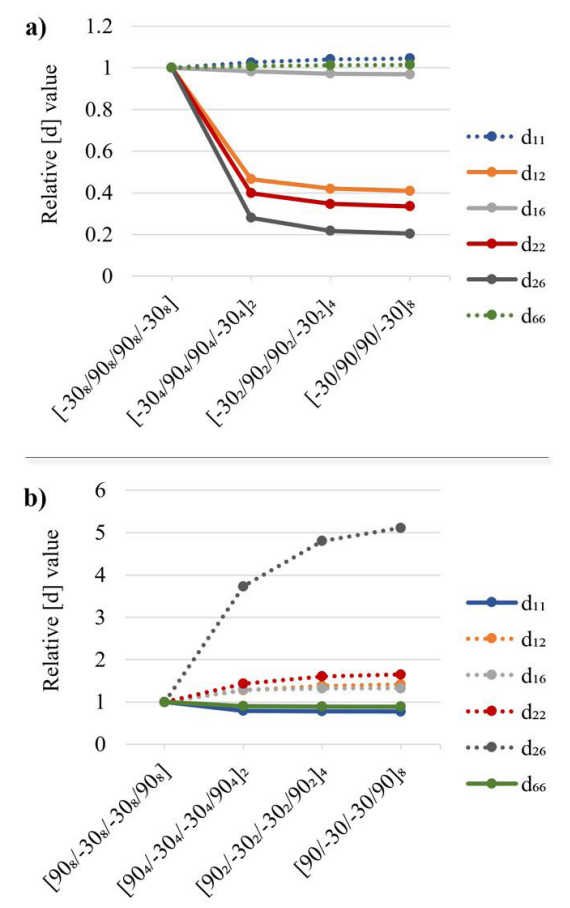

Fig. 6 The effect of layup homogenization on the $[d]$ matrix values: a) $\left[-30_{8 / \mathrm{n}} / 90_{8 / \mathrm{n}} / 90_{8 / \mathrm{n}} /-\right.$ $\left.30_{8 / \mathrm{n}}\right]_{\mathrm{n}}$, b) $\left[90_{8 / \mathrm{n}} /-30_{8 / \mathrm{n}} /-30_{8 / \mathrm{n}} / 90_{8 / \mathrm{n}}\right]_{\mathrm{n}}(\mathrm{n}=1,2,4$,

8). Increasing values marked with dotted line, decreasing values with continuous line

\section{Conclusions}

Through analytical calculations based on the Classical Laminate Theory, we showed the importance of multi-parameter layup optimization of coupled laminates. The properties of composites are affected by the layup structure, and different parameters change differently with the layup. Because of this, a full-field layup optimization - where the behaviour of all possible layup permutations is calculated - is useful to find patterns in the results and compare local optimums to each other. The example laminate was optimized for a helicopter rotor blade with maximum possible extension-twist performance, adequate bending stiffness and negligible thermal warpage. The upper limits of both bending compliance and warpage lowered the achievable desired extension-twist behaviour, but warpage was significantly more limiting. This can be explained by the fact that both extension-twist and warpage are driven by the values of the $[b]$ matrix, while bending compliance is a term in the [d] matrix. Therefore, the first two parameters are related more closely to each other. One of the most important conclusions of the multi-parameter optimization study is that asymmetric laminates can provide notable coupling performance while not worsening other important properties significantly. The main reason why the composites industry avoids asymmetric layups is their thermal warpage, but we showed that these layups can provide a significant amount of the maximum achievable extension-twist performance with practically negligible warpage. Symmetric laminates do not possess any of this coupling behaviour intrinsically. This is another evidence that the advantages of asymmetric laminates far outweigh their disadvantages in many applications.

In the second part of the paper, we showed that layup homogenization does not have a universal effect on the values of the bending compliance matrix $([d])$. This is important as it proves that any term in that $[d]$ matrix can be increased or reduced with homogenization depending on the layup of the sub-laminate. From a practical standpoint, layup homogenization can mitigate the thermal warpage of asymmetric laminates while reducing the bending compliance $\left(d_{11}\right)$ or increasing the bend-twist performance $\left(d_{16}\right)$ of the laminate, for instance. This is another feature of the layup homogenization method that can be exploited to design composites with advanced mechanical properties.

Future research efforts should focus on multi-parameter layup optimizations, where bistability of the warped laminates is considered. Also, it is essential to determine the quantitative effect of layup homogenization on the $[d]$ matrix values of various layups to draw further conclusions on the usefulness of the method. 


\section{Acknowledgement}

The research reported in this paper is part of project no. BME-NVA-02, implemented with the support provided

\section{References}

[1] Czél, G., Wisnom, M. R. "Demonstration of pseudo-ductility in high performance glass/epoxy composites by hybridization with thin-ply carbon prepreg", Composites Part A: Applied Science and Manufacturing, 52, pp. 23-30, 2013.

https://doi.org/10.1016/j.compositesa.2013.04.006

[2] Wu, X., Fuller, J. D., Wisnom, M. R. "Role of fibre fragmentation on pseudo-ductility of thin-ply $[ \pm 277 / 0]$ s carbon fibre laminates with high modulus $0^{\circ}$ plies under compressive and flexural loading", Composites Science and Technology, 199, Article number: 108377, 2020.

https://doi.org/10.1016/j.compscitech.2020.108377

[3] Magyar, B., Czigany, T., Szebényi, G. "Metal-alike polymer composites: The effect of inter-layer content on the pseudo-ductile behaviour of carbon fibre/epoxy resin materials", Composites Science and Technology, 215, Article number: 109002, 2021. https://doi.org/10.1016/j.compscitech.2021.109002

[4] Pozegic, T. R., Fotouhi, M., Wu, X., Hartley, J. W., Wisnom, M. R., Hamerton, I. "Pseudo-ductile behaviour in fibre reinforced thermoplastic angle-ply composites", Composites Science and Technology, 197, Article number: 108261, 2020.

https://doi.org/10.1016/j.compscitech.2020.108261

[5] Marino, S. G., Czél, G. "Improving the performance of pseudo-ductile hybrid composites by film-interleaving", Composites Part A: Applied Science and Manufacturing, 142, Article number: 106233, 2021.

https://doi.org/10.1016/j.compositesa.2020.106233

[6] Li, T., Liu, F., Wang, L. "Enhancing indentation and impact resistance in auxetic composite materials", Composites Part B: Engineering, 198, Article number: 108229, 2020.

https://doi.org/10.1016/j.compositesb.2020.108229

[7] Ahmad, F., Abbassi, F., Ul-Islam, M., Jacquemin, F., Hong, J. W. "Enhanced impact-resistance of aeronautical quasi-isotropic composite plates through diffused water molecules in epoxy", Scientific Reports, 11(1), Article number: 1775, 2021.

https://doi.org/10.1038/s41598-021-81443-w

[8] Pomázi, Á., Toldy, A. "Development of fire retardant epoxy-based gelcoats for carbon fibre reinforced epoxy resin composites", Progress in Organic Coatings, 151, Article number: 106015, 2021. https://doi.org/10.1016/j.porgcoat.2020.106015

[9] Wang, D. Y. (ed.) "Novel Fire Retardant Polymers and Composite Materials", Woodhead Publishing, Duxford, UK, 2016.

[10] Duarah, R., Deka, A., Karak, N. "Multifaceted bioinspired hyperbranched polyurethane nanocomposite as a non-contact triggered self-healing material", Express Polymer Letters, 14(6), pp. 542-555, 2020.

https://doi.org/10.3144/expresspolymlett.2020.44

[11] Blaiszik, B. J., Kramer, S. L. B., Olugebefola, S. C., Moore, J. S., Sottos, N. R., White, S. R. "Self-Healing Polymers and Composites", Annual Review of Materials Research, 40(1), pp. 179-211, 2010. https://doi.org/10.1146/annurev-matsci-070909-104532 by the Ministry of Innovation and Technology of Hungary from the National Research, Development and Innovation Fund, financed under the TKP2021 funding scheme.

[12] Forintos, N., Sarkadi, T., Czigany, T. "Electric resistance measurement-based structural health monitoring with multifunctional carbon fibers: Predicting, sensing, and measuring overload", Composites Communications, 28, Article number: 100913, 2021. https://doi.org/10.1016/j.coco.2021.100913

[13] Mueller, I., Das, S., Roy, S., Janapati, V., Vonnieda, K., Zhang, D., Chang, F. K. "An integrated health management system for realtime impact monitoring and prediction of impact-induced damage on composite structures", In: Health Monitoring of Structural and Biological Systems 2010, San Diego, CA, USA, 2010, Article number: 76501D.

https://doi.org/10.1117/12.849667

[14] York, C. "Unified approach to the characterization of coupled composite laminates: Hygro-thermally curvature-stable configurations", International Journal of Structural Integrity, 2(4), pp. 406-436, 2012.

https://doi.org/10.1108/17579861111183920

[15] York, C. B. "On Extension-Shearing coupled laminates", Composite Structures, 120, pp. 472-482, 2015.

https://doi.org/10.1016/j.compstruct.2014.10.019

[16] York, C. B. "On Bending-Twisting coupled laminates", Composite Structures, 160, pp. 887-900, 2017.

https://doi.org/10.1016/j.compstruct.2016.10.063

[17] York, C. B. "Extension-Twist coupled laminates for aero-elastic compliant blade design", In: 53rd AIAA/ASME/ASCE/AHS/ ASC Structures, Structural Dynamics and Materials Conference, Honolulu, HI, USA, 2012, Article number: AIAA 2012-1457. https://doi.org/10.2514/6.2012-1457

[18] Murray, R. E., Doman, D. A., Pegg, M. J. "Finite element modeling and effects of material uncertainties in a composite laminate with bend-twist coupling", Composite Structures, 121, pp. 362-376, 2015.

https://doi.org/10.1016/j.compstruct.2014.11.035

[19] Nicholls-Lee, R. F., Turnock, S. R., Boyd, S. W. "Application of bend-twist coupled blades for horizontal axis tidal turbines", Renewable Energy, 50, pp. 541-550, 2013. https://doi.org/10.1016/j.renene.2012.06.043

[20] Motley, M. R., Liu, Z., Young, Y. L. "Utilizing fluid-structure interactions to improve energy efficiency of composite marine propellers in spatially varying wake", Composite Structures, 90(3), pp. 304-313, 2009. https://doi.org/10.1016/j.compstruct.2009.03.011

[21] Belhadj, B., Abdelkader, L., Chateauneuf, A. "Weibull Probabilistic Model of Moisture Concentration Build Up in a Fiber Graphite/Epoxy Polymer Composite under Varying Hydrothermal Conditions", Periodica Polytechnica Mechanical Engineering, 65(1), pp. 27-37, 2021. https://doi.org/10.3311/PPme.13653 
[22] Tseng, S. C., Osswald, T. A. "Prediction of Shrinkage and Warpage of Fiber Reinforced Thermoset Composite Parts", Journal of Reinforced Plastics and Composites, 13(8), pp. 698-721, 1994. https://doi.org/10.1177/073168449401300803

[23] Cross, R. J., Haynes, R. A., Armanios, E. A. "Families of Hygrothermally Stable Asymmetric Laminated Composites", Journal of Composite Materials, 42(7), pp. 697-716, 2008. https://doi.org/10.1177/0021998308088597

[24] Haynes, R. A., Armanios, E. A. "New Families of Hygrothermally Stable Composite Laminates with Optimal Extension-Twist Coupling", AIAA Journal, 48(12), pp. 2954-2961, 2010. https://doi.org/10.2514/1.J050596

[25] Barbero, E. J. "Introduction to Composite Materials Design", CRC Press, Boca Raton, FL, USA, 2017. https://doi.org/10.1201/9781315296494

[26] Tsai, S. W., Melo, J. D. D. "Composite Materials Design and Testing: Unlocking mystery with invariants", Composites Design Group, Stanford, CA, USA, 2015.

[27] Vermes, B., Tsai, S. W., Massard, T., Springer, G. S., Czigany, T. "Design of laminates by a novel "double-double" layup", ThinWalled Structures, 165, Article number: 107954, 2021. https://doi.org/10.1016/j.tws.2021.107954
[28] Hodges, D. H. "Nonlinear Composite Beam Theory", American Institute of Aeronautics and Astronautics, Virginia, USA, 2006. https://doi.org/10.2514/4.866821

[29] Kollár, L. P., Pluzsik, A. "Bending and torsion of composite beams (torsional-warping shear deformation theory)", Journal of Reinforced Plastics and Composites, 31(7), pp. 441-480, 2012. https://doi.org/10.1177/0731684412437611

[30] Kollár, L. P., Springer, G. S. "Mechanics of Composite Structures", Cambridge University Press, Cambridge, UK, 2003. https://doi.org/10.1017/CBO9780511547140

[31] Hyer, M. W. "Calculations of the Room-Temperature Shapes of Unsymmetric Laminatestwo", Journal of Composite Materials, 15(4), pp. 296-310, 1981. https://doi.org/10.1177/002199838101500401

[32] Hyer, M. W. "The Room-Temperature Shapes of Four-Layer Unsymmetric Cross-Ply Laminates", Journal of Composite Materials, 16(4), pp. 318-340, 1982. https://doi.org/10.1177/002199838201600406

[33] International Organization for Standardization "ISO 2768-General Geometrical Tolerances and Technical Drawings", International Organization for Standardization, Geneva, Switzerland, 1989. 